\title{
The mediating role of psychological capital between Dayadi stress and job burnout in female nurses with two children
}

\author{
Xiaoyan Zhu", Liwen Shen", Peihong Du", Juan Guan \\ Emergency Department, the Sixth People's Hospital, affiliated with Shanghai Jiao Tong University, Shanghai, China \\ Contributions: (I) Conception and design: X Zhu; (II) Administrative support: L Shen; (III) Provision of study materials or patients: L Shen, P Du; (IV) \\ Collection and assembly of data: All authors; (V) Data analysis and interpretation: L Shen, P Du; (VI) Manuscript writing: All authors; (VII) Final \\ approval of manuscript: All authors. \\ \#These authors contributed equally to this work. \\ Correspondence to: Xiaoyan Zhu. Emergency Department, the Sixth People's Hospital, affiliated to Shanghai Jiao Tong University, 600 Yishan Road, \\ Shanghai 200233, China. Email: myself85@163.com.
}

Background: This study aims to understand the job burnout status of female nurses with two children and explore the mediating role of psychological capital between dyadic stress and job burnout.

Methods: We used a random sampling method to select 386 female nurses with two children from four tertiary level hospitals between July and October 2020. A general data questionnaire, dyadic stress scale, psychological capital scale, and job burnout scale were used for the investigation and analysis.

Results: The psychological capital score of nurses with two children was $84.87 \pm 15.45$, the dyadic stress was $34.48 \pm 6.18$, and the job burnout score was $68.28 \pm 14.28$. Factors affecting the binary stress score, psychological capital score, and job burnout score of nurses with two children included age, professional title, length of service, monthly income, age of the first child, the type of childcare arrangements, and hospital department. The psychological capital score was negatively correlated with the job burnout score $(\mathrm{r}=-0.617$, $\mathrm{P}<0.01)$. There was a positive correlation between the dyadic stress score and the job burnout score $(\mathrm{r}=0.539$, $\mathrm{P}<0.01)$, and a negative correlation between the psychological capital score and the binary stress score $(\mathrm{r}=-0.528, \mathrm{P}<0.01)$. The mediating effect of psychological capital was 0.199 , accounting for $36.71 \%$ of the total effect.

Conclusions: The results showed that dyadic stress and job burnout in nurses with two children were at a high level and that psychological capital played a partial mediating role between binary stress and job burnout.

Keywords: Two children; job burnout; dyadic stress; nurses; psychological capital

Submitted Jul 21, 2021. Accepted for publication Sep 18, 2021.

doi: $10.21037 /$ tp-21-375

View this article at: https://dx.doi.org/10.21037/tp-21-375

\section{Introduction}

Since China's second-child policy was implemented in 2016, the number of female hospital nurses with two children has increased significantly. These female nurses are the backbone of the nursing team and have extensive work experience and professional skills (1). However, having a second child presents significant challenges in balancing work and family for this population. Studies have reported that female nurses with two children experience a higher level of work-family conflict (2), and this increase in workfamily conflict can aggravate nurses' occupational pressure and lead to an increase in job burnout $(3,4)$. Alleviating job burnout in female nurses with two children is a key issue that nursing managers urgently need to address. The concept of dyadic stress refers to the shared impact of 
stress on both partners in a relationship, i.e., an external or internal pressure that the partners jointly encounter. Alternatively, one partner may experience stress that impacts the intimate relationship and hence affects both parties (5). As an external pressure, the pressure related to raising children can create dyadic stress by way of conflicts and quarrels. However, there are currently no studies on the correlation between dyadic stress and job burnout in China. The concept of psychological capital is derived from positive psychology and denotes a positive mental state that a person exhibits due to personal growth or development (6). Studies have shown that psychological capital can effectively relieve nurses' job stress and reduce their job burnout $(7,8)$. Therefore, this study aims to investigate the job burnout status of female nurses with two children, explore the mediating role of psychological capital between dyadic stress and job burnout, and provide a reference for formulating targeted measures to reduce the level of job burnout in female nurses with two children. We present the following article in accordance with the SURGE reporting checklist (available at https://dx.doi. org/10.21037/tp-21-375).

\section{Methods}

\section{Subjects}

A total of 386 female nurses with two children from four tertiary level hospitals in Shanghai were randomly selected as the survey subjects between July and October 2020 . Inclusion criteria were as follows: (I) female nurses who had given birth to two children and had been engaged in clinical nursing for more than 1 year and were still on duty; (II) the two children of the female nurses had no significant diseases or serious congenital diseases; (III) a period of 6 months or more since giving birth to the second child; (IV) the return-to-work time was $\geq 6$ months. The exclusion criteria were as follows: trainee nurses, or those who had not obtained a vocational nursing qualification certificate, and two-child female nurses who were not currently working. All procedures performed in this study involving human participants were in accordance with the Declaration of Helsinki (as revised in 2013). This survey was approved by the Medical Ethics Committee of the Sixth People's Hospital affiliated with Shanghai Jiaotong University [2021-KY-70(K)], and all survey subjects participated in this survey voluntarily and informed consent was taken from all the participants.

\section{Survey tools}

\section{Demographic information questionnaire}

Demographic data were collected using a self-designed demographic questionnaire, including age, education, professional title, department, monthly income, establishment, second-child care arrangements, and age of the first and second child.

\section{Dyadic stress scale}

The translated and revised Multidimensional Stress Questionnaire for Couples (9) was used to evaluate the dyadic stress status of nurses with two children. The scale is divided into two dimensions of internal pressure (10 items) and external pressure (8 items), with a total of 18 items. Each item was scored using a 4-point scoring scale (1-4 points), with a total scoring range of $18-72$ points. The higher the internal pressure dimension score, the greater the internal pressure; the higher the external pressure dimension score, the greater the external pressure. The preliminary survey results showed that the Cronbach $\alpha$ coefficient of the scale was 0.836 .

\section{Occupational burnout scale}

The occupational burnout scale compiled by $\mathrm{Li}$ et al. (10) was used for nurses who had given birth to two children. The scale is composed of three dimensions and 22 items in all, including emotional exhaustion (9 items), depersonalization (5 items), and personal accomplishment (8 items). A Likert 7 -point scoring method was used for evaluating each item from 0-6 points. The total score ranged from $0-132$ points. The higher the score, the higher the level of job burnout. The Cronbach $\alpha$ coefficient of this scale was 0.842 , indicating good reliability and validity.

\section{Psychological capital scale}

The psychological capital of nurses with two children was investigated using the Nurse Psychological Capital Scale compiled and revised by Luo et al. (11). The scale consists of four dimensions and a total of 20 items, including selfefficacy (5 items), optimism (5 items), hope (5 items), and resilience (5 items). A Likert 6-point scoring method was used to score each item from 1-6 points. The total score ranged from $20-120$ points. The higher the score, the higher the level of psychological capital. The Cronbach $\alpha$ coefficient of the scale was 0.966 , indicating good reliability and validity. 


\section{The survey method}

Questionnaires were used as the primary survey method and were administered by uniformly trained nurses. All investigators used standardized instructions to introduce the purpose, content, meaning, and method of filling out the questionnaires to the respondents. Two questions were set in the questionnaire, and one or two wrong answers will be regarded as invalid questionnaire. The respondents were asked to complete the questionnaire within 10 to 30 minutes. The investigator on-site checks whether the questionnaire was completely filled in, whether there were incorrect items, logical order and lie detector questions.

\section{Statistical analysis}

Epidata 3.1 software was used to establish a database to import the questionnaires. The measurement data were expressed as the mean \pm standard deviation $(\bar{x} \pm s)$ and analyzed using SPSS 22.0 software (IBM, New York, USA). A Pearson correlation analysis was used to analyze the correlation between binary stress, psychological capital, and job burnout. The stepwise regression proposed by Wen and Ye (12) was used to analyze the mediating effect of psychological capital on dyadic stress and job burnout and was verified using AMOS 23.0 software (13). Results with a $P$ value $<0.05$ were considered statistically significant.

\section{Results}

\section{Demographic information}

The demographic information of the 386 nurses with two children was as follows: age: 162 cases $(41.97 \%)$ were 26-32 years old, 128 cases (33.16\%) were 33-39 years old, and 96 cases $(24.87 \%)$ were $\geq 40$ years old; educational level: $204(52.85 \%)$ were college students, $182(47.15 \%)$ were undergraduates and above; titles: 203 cases $(52.59 \%)$ had junior titles, 155 cases $(40.16 \%)$ had intermediate titles, and 28 cases $(7.25 \%)$ had senior titles; length of service: 178 (46.11\%) had been employed for $<5$ years, 142 (36.79\%) had been employed for 5-10 years, and 66 (17.10\%) had been employed for $>10$ years; monthly income: 181 cases $(46.89 \%)$ earned $<5,000$ yuan, 146 cases $(37.82 \%)$ earned 5,000-10,000 yuan, and 59 cases (15.28\%) earned $>10,000$ yuan; department: 71 cases $(18.39 \%)$ worked in the department of internal medicine, 82 cases $(21.24 \%)$ worked in the department of surgery, 62 cases $(16.06 \%)$ worked in the department of obstetrics and gynecology, 74 cases
(19.17\%) worked in the department of pediatrics, 81 cases $(20.89 \%)$ worked in the department of ICU and emergency, and the remaining 16 cases worked in other departments and accounted for $4.14 \%$.

\section{Psychological capital, dyadic stress, and job burnout scores of nurses with two children}

The psychological capital score of the nurses with two children was $84.87 \pm 15.45$, the dyadic stress score was $34.48 \pm 6.18$, and the job burnout score was $68.28 \pm 14.28$. The scores for each dimension are shown in Table 1 .

\section{Psychological capital, dyadic stress, and job burnout scores of nurses with different demographic characteristics}

The scores of two-child nurses of different ages, professional titles, years of service, monthly income, age of first child, two-child care arrangements, and hospital departments showed statistically significant differences in binary stress and job burnout (both $\mathrm{P}<0.05$ ). The psychological capital scores of two-child nurses of different ages, years of service, professional titles, and monthly income were also significantly different $(\mathrm{P}<0.05)($ Table 2$)$.

\section{The correlation of psychological capital, dyadic stress, and job burnout among nurses with two children}

The psychological capital score of nurses with two children was negatively correlated with the job burnout score $(\mathrm{r}=-0.617, \mathrm{P}<0.01)$. The dyadic stress score was positively correlated with the job burnout score $(\mathrm{r}=0.539, \mathrm{P}<0.01)$. The psychological capital score was negatively correlated with the dyadic stress score $(\mathrm{r}=-0.528, \mathrm{P}<0.01)$. Details are shown in Table 3.

\section{The mediating role of psychological capital between dyadic stress and job burnout in nurses with two children}

\section{Mediation effect test}

The stepwise regression method was used to analyze the mediating role of psychological capital between dyadic stress and job burnout in nurses with two children. The results showed that the regression coefficients $a, b$, c, and c' were all statistically significant $(\mathrm{P}<0.01)$, indicating that psychological capital played a partial mediating role between dyadic stress and job burnout of nurses with two children. The mediating effect was $(-0.441) \times(-0.452)=0.199$, 
Table 1 Psychological capital, dyadic stress, and job burnout scores of nurses with two children $(\mathrm{n}=386)$

\begin{tabular}{lcccc}
\hline Content & Item & Lowest score & Highest score & Score $(\bar{x} \pm$ S $)$ \\
\hline Psychological capital & 20 & 66 & 114 & 28 \\
Hope & 5 & 12 & 29 & $22.42 \pm 6.38$ \\
Optimism & 5 & 14 & 26 & $20.28 \pm 7.42$ \\
Tenacity & 5 & 10 & 28 & $18.13 \pm 6.74$ \\
Self-efficacy & 5 & 12 & 48 & $24.04 \pm 7.16$ \\
Dyadic stress & 18 & 22 & 26 & $34.48 \pm 6.18$ \\
External pressure & 8 & 12 & 29 & $16.42 \pm 4.26$ \\
Internal pressure & 10 & 15 & 102 & $18.06 \pm 5.14$ \\
Job burnout & 22 & 58 & 48 & $68.28 \pm 14.28$ \\
Emotional exhaustion & 9 & 18 & 26 & $29.86 \pm 6.82$ \\
Depersonalization & 5 & 12 & 42 & $12.24 \pm 4.26$ \\
Personal achievement & 8 & 14 & $26.18 \pm 5.72$ \\
\hline
\end{tabular}

and the ratio of the mediating effect to the total effect was: $0.199 / 0.542 \times 100 \%=36.71 \%$ (Table 4).

\section{Intermediary effect verification}

A structural equation model was constructed with dyadic stress as the predictive variable, psychological capital as the mediating variable, and job burnout as the dependent variable, as shown in Figure 1. This model was constructed to investigate the fit between the model and the data. The results were as follows:

$2<$ Chi-square degree of freedom ratio $\left(\chi^{2} / \mathrm{df}\right)=2.718<5$, root mean square error of approximation asymptotic $($ RMSEA $)=0.072<0.08$, residual mean square root $(\mathrm{RMR})$ $=0.024<0.05$; increase fitting index $($ IFI $)=0.93$, adjusted goodness of fit index $(\mathrm{AGFI})=0.96$, Tucker-Lewis index $(\mathrm{TLI})=0.92$, normalized fitting index $(\mathrm{NFI})=0.93$, comparable fit index $(\mathrm{CFI})=0.94$, goodness of fit index $(\mathrm{GFI})$ $=0.93$. These indexes were all $>0.90$, indicating that the data were a good fit with the model. The Bootstrap method was used to test the mediating effect of psychological capital on dyadic stress and job burnout. The results showed that the direct effect, indirect effect, and total effect of dyadic stress on job burnout did not include 0 in the $95 \%$ CI. It can be seen that the structural equation model of the partial mediating effect of psychological capital between dyadic stress and job burnout was established successfully.

\section{Discussion}

\section{Psychological capital, dyadic stress, and job burnout in nurses with two children}

This survey showed that the psychological capital score of nurses with two children was $84.87 \pm 15.45$, which is relatively high. These results are similar to the findings of a previous study that reported a psychological capital score of $86.62 \pm 10.59$ for nurses in a tertiary level hospital setting (14). These psychological capital scores might be attributed to the following factors: (I) the caring profession of nursing is well-regarded, and nurses have positive expectations and a more optimistic attitude toward their career; (II) nurses with two children are generally well-qualified with extensive work experience and enthusiasm for their job, and show strong resilience in dealing with frustration and pressure; (III) nurses with two children demonstrate their maternal instinct in their nursing role and can integrate their emotions into work. They will experience a high sense of personal achievement when they see patients recover due to their care at work. Therefore, their level of psychological capital is relatively high. The results of this survey also showed that the psychological capital scores of two-child nurses differed according to age, years of service, job title, and monthly income $(\mathrm{P}<0.05)$, which is consistent with the results reported in the literature (15). 
Table 2 Psychological capital, dyadic stress, and job burnout scores of two-child nurses with different demographic characteristics ( $\mathrm{n}=386$ )

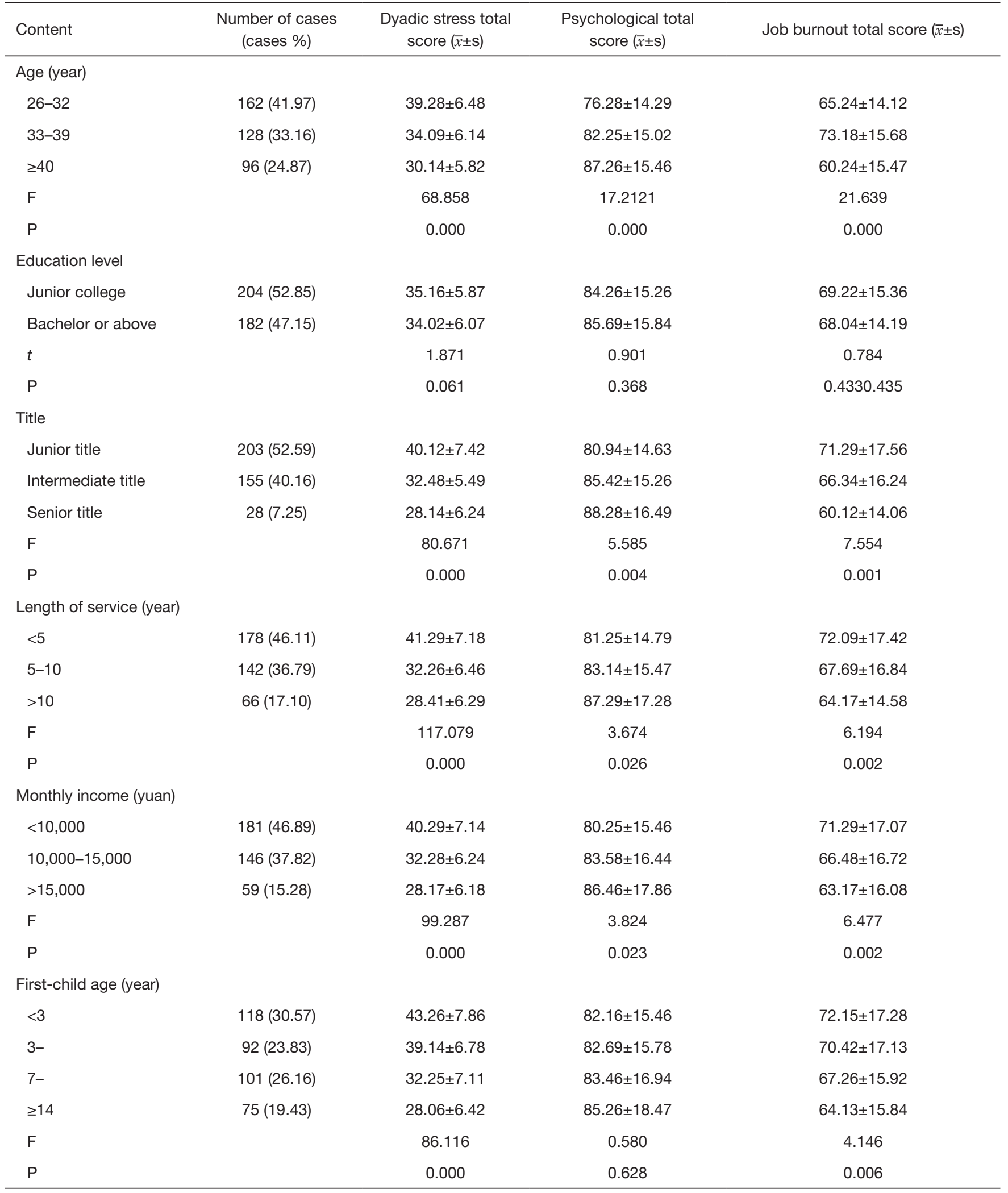

Table 2 (continued) 
Table 2 (continued)

\begin{tabular}{|c|c|c|c|c|}
\hline Content & $\begin{array}{c}\text { Number of cases } \\
\text { (cases \%) }\end{array}$ & $\begin{array}{c}\text { Dyadic stress total } \\
\text { score }(\bar{x} \pm \mathrm{s})\end{array}$ & $\begin{array}{l}\text { Psychological total } \\
\text { score }(\bar{x} \pm s)\end{array}$ & Job burnout total score $(\bar{x} \pm s)$ \\
\hline \multicolumn{5}{|l|}{$\begin{array}{l}\text { Two-child care } \\
\text { arrangement }\end{array}$} \\
\hline Parents & $162(41.97)$ & $29.15 \pm 6.29$ & $83.49 \pm 16.85$ & $63.02 \pm 15.66$ \\
\hline Housekeeper & $181(46.89)$ & $32.13 \pm 6.02$ & $85.96 \pm 17.28$ & $66.12 \pm 15.09$ \\
\hline $\mathrm{F}$ & & 52.881 & 0.897 & 4.045 \\
\hline $\mathrm{P}$ & & 0.000 & 0.408 & 0.018 \\
\hline \multicolumn{5}{|l|}{ Department } \\
\hline Internal medicine & 71 (18.39) & $30.15 \pm 6.48$ & $84.68 \pm 15.86$ & $63.09 \pm 15.18$ \\
\hline Pediatric & $74(19.17)$ & $36.45 \pm 5.78$ & $82.62 \pm 15.74$ & $65.47 \pm 12.48$ \\
\hline ICU/Emergency & $81(20.98)$ & $39.42 \pm 7.46$ & $81.17 \pm 16.08$ & $72.28 \pm 17.45$ \\
\hline Others & $16(4.14)$ & $29.14 \pm 5.94$ & $83.41 \pm 16.44$ & $60.17 \pm 15.64$ \\
\hline $\mathrm{F}$ & & 24.318 & 0.367 & 4.371 \\
\hline $\mathrm{P}$ & & 0.000 & 0.871 & 0.001 \\
\hline
\end{tabular}

Therefore, nursing managers should pay more attention to the psychological capital status of nurses with two children. While strengthening nurses' professional capabilities, they should also pay attention to the psychological wellbeing of nurses. For nurses with two children, due to family environment changes, taking two children takes a lot of leisure time of the nurses, leading to no time left for participating in the hospital organization of all kinds of psychological capital training. So nurses with two children can obtain psychological capital related knowledge and information according to their own spare time through the combination of network. Hospital nursing managers can set up psychological capital network training courses for second-child nurses to improve their psychological capital. Enhancing the psychological resilience of young nurses, nurses with little working experience, or those on low incomes is important in reducing job burnout and binary stress. Psychological capital in nurses could be improved by strategies such as theoretical training and talent training.

This survey showed that the dyadic stress score of nurses with two children was $34.48 \pm 6.18$, which is at a moderate level but higher than the results of the study by Kurosawa et al. (9). The possible reasons are as follows: on the one hand, nurses who have had a second child face external pressures such as work pressure, financial pressure, and child-related pressure; on the other hand, they may also experience internal pressure from their spouses, such as taking on family affairs, daily conflicts, and relationship tensions caused by childcare or pressure due to the health of their partner. Therefore, the dyadic stress of nurses with two children is relatively high. The survey results also showed that the dyadic stress scores of two-child nurses differed according to age, job title, years of service, monthly income, age of the first child, two-child care arrangements, and department $(\mathrm{P}<0.05)$, indicating that the dyadic stress of nurses is the result of multiple factors and conditions. As a result, nursing managers may need to carry out targeted intervention measures according to the demographic characteristics and work status of nurses who have had two children to reduce their dyadic stress.

The survey results also showed that the job burnout score of nurses with two children was $68.28 \pm 14.28$, which is relatively high and higher than the results reported in previous studies $(16,17)$. Nurses who have two children 


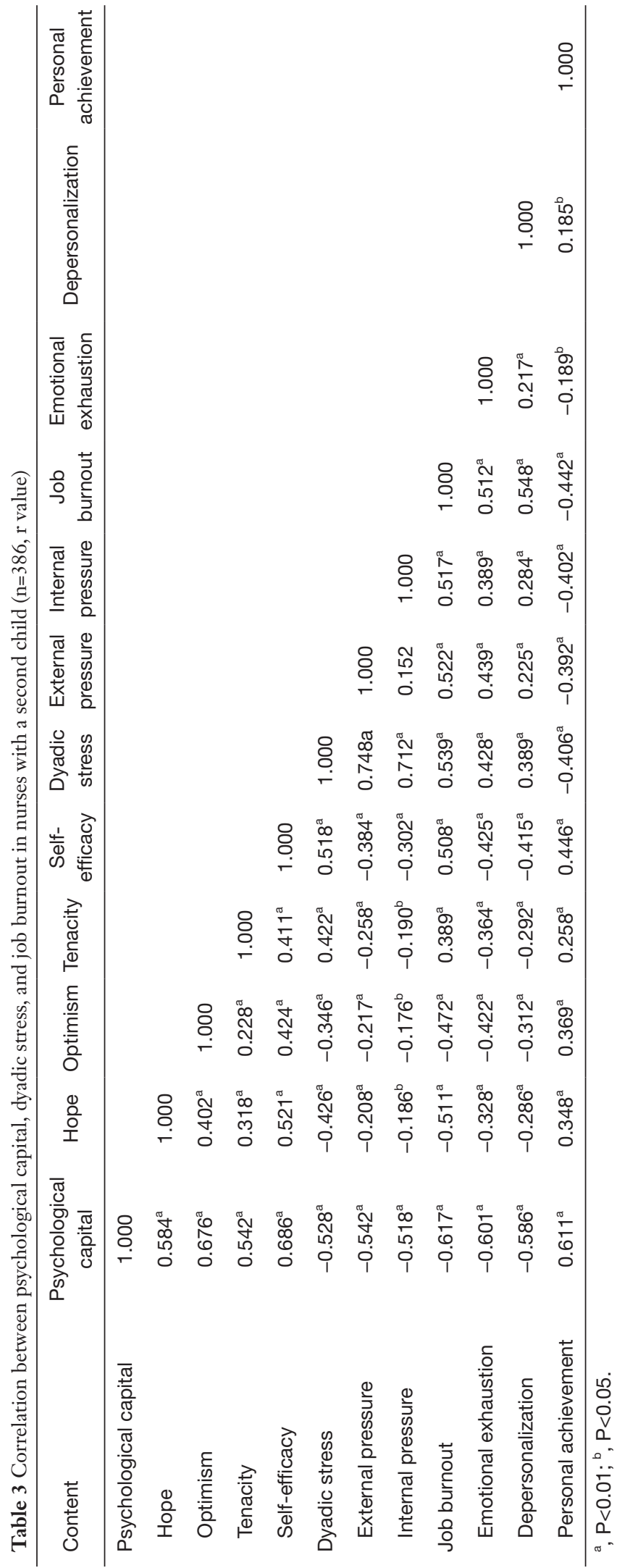

may play multiple roles at work, such as caregivers, health consultants, and managers, and they also assume multiple social roles, such as wives and mothers, in their personal life. When a variety of existing roles conflict, it can easily lead to more pressure, causing higher job burnout (2). The survey results also showed that job burnout scores of twochild nurses differed according to age, job title, years of service, monthly income, first-child age, two-child care arrangements, and department $(\mathrm{P}<0.05)$, consistent with previous literature $(18,19)$. We can see that the job burnout level of nurses with two children is relatively high. To reduce job burnout amongst these nurses, hospital care managers should pay more attention to nurses with two children when formulating management strategies. In particular, two-child nurses who are younger, have less work experience, are in junior positions, have lower incomes, work in ICU or emergency departments, have a younger first child, or whose childcare is provided by non-parents or housekeepers, will require extra support such as through anti-pressure ability training, challenge the work content, increase the psychological endurance and coping ability of nurses who have two children in the face of complex working environment. Nursing managers can adopt flexible working system to reduce the working pressure of nurses who have a second child, and strive for the support of nurses' spouses, help them contact childcare services, and organize childcare classes in winter and summer holidays; creating a good team atmosphere, providing more rest time between shifts and sufficient manpower can all reduce the working pressure of nurses with two children; maintaining good communication with nurses with two children, attaching importance to the support of nurses' families and taking positive measures to alleviate or eliminate conflicts can improve their family functions, reduce the work pressure of these nurses, and reduce the level of job burnout.

\section{The correlation of psychological capital, dyadic stress, and job burnout among nurses with two children}

The results of this survey showed that the psychological capital score of nurses with two children was negatively correlated with the job burnout score $(\mathrm{P}<0.01)$, indicating that a higher level of psychological capital in nurses with two children was associated with a lower job burnout level, consistent with previous reports (20). Psychological capital is a positive psychological resource. The more abundant the psychological resource of nurses who have given birth 
Table 4 The sequential regression coefficient of the mediating effect of psychological capital in nurses with two children on the relationship between dyadic stress and job burnout

\begin{tabular}{lcccc}
\hline Step & Dependent variable & Independent variable & Normalized regression equation & Regression coefficient test \\
\hline Step 1 & Job burnout $(\mathrm{Y})$ & Dyadic stress $(\mathrm{X})$ & $\mathrm{Y}=0.542 \mathrm{X}(\mathrm{c}=0.542)$ & $\mathrm{SE}=0.043, t=12.606^{\mathrm{a}}$ \\
Step 2 & Psychological capital $(\mathrm{M})$ & Dyadic stress $(\mathrm{X})$ & $\mathrm{M}=-0.441 \mathrm{X}(\mathrm{a}=-0.441)$ & $\mathrm{SE}=0.041, t=-10.756^{\mathrm{a}}$ \\
Step 3 & Job burnout $(\mathrm{Y})$ & Psychological capital $(\mathrm{M})$ & $\mathrm{Y}=-0.452 \mathrm{M}+0.343 \mathrm{X} ; \mathrm{b}=-0.452$, & $\mathrm{SE}=0.039, t=-11.590^{\mathrm{a}}$ \\
& & Dyadic stress $(\mathrm{X})$ & $\mathrm{c}^{\prime}=0.343$ & $\mathrm{SE}=0.039, t=8.795^{\mathrm{a}}$ \\
\hline
\end{tabular}

${ }^{\mathrm{a}}, \mathrm{P}<0.01 . \mathrm{SE}$, standard error.

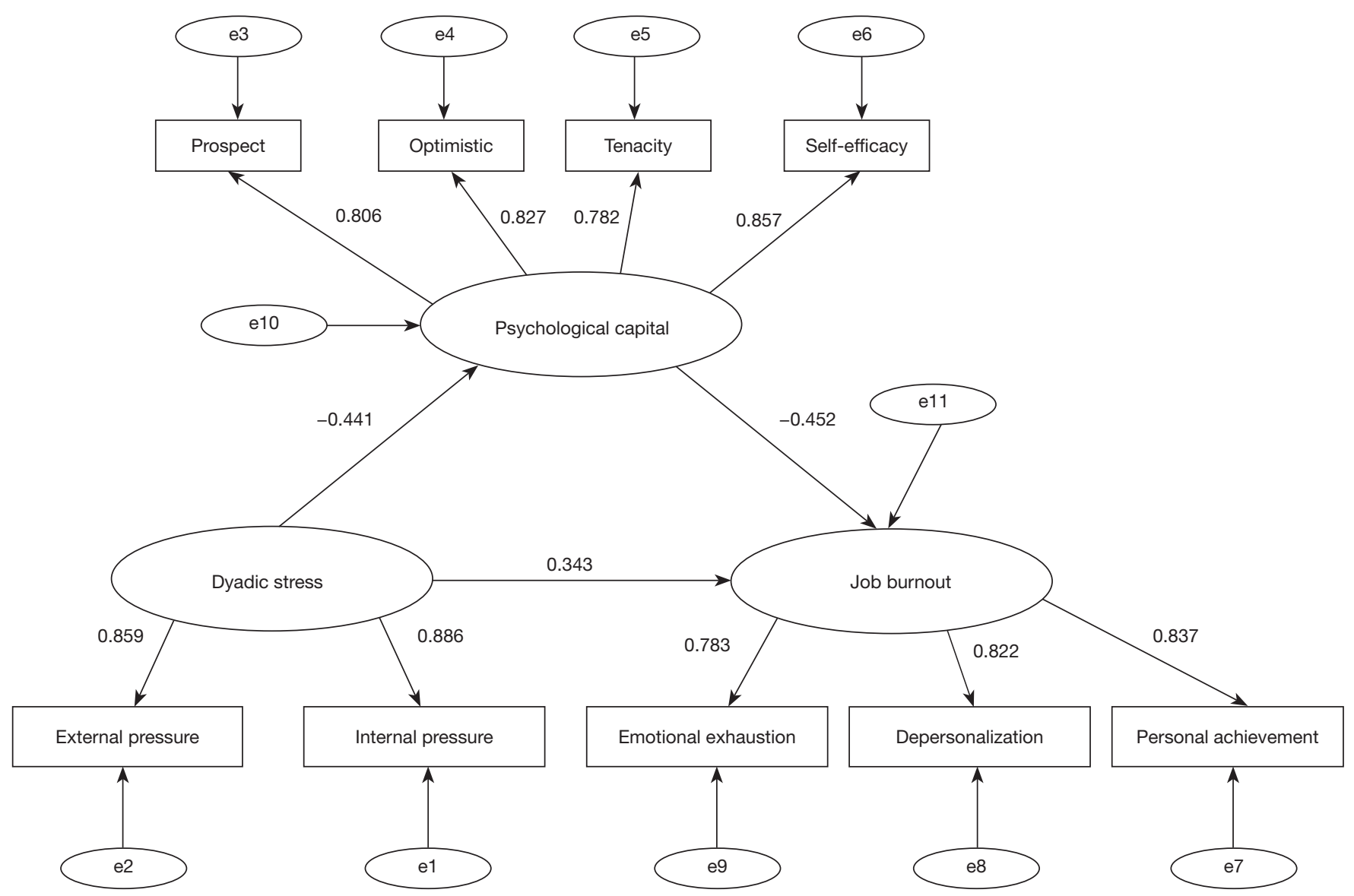

Figure 1 Structural equation model of the mediating effect of psychological capital in nurses with two children on the relationship between dyadic stress and job burnout. e1-e11 are residuals. The data in the figure are the standardized path coefficients, and the $\mathrm{P}$ values of all the path coefficients are $<0.01$.

to two children, the more they can effectively deal with work challenges. In this way they are able to adopt positive coping strategies to alleviate the negative psychological emotions caused by stress and reduce job burnout. In addition, two-child nurses with higher psychological capital can deal with work and family from a more positive perspective, balance the conflict between work and family, and reduce job burnout. Our survey results showed that the dyadic stress score of nurses with two children was positively correlated with the job burnout score $(\mathrm{P}<0.01)$, indicating that higher binary stress was associated with higher job burnout. Nurses with two children and their 
spouses regard parenting-related pressure as binary stress, i.e., "shared stress." Appropriate dyadic stress is conducive to increasing cohesion, mutual trust, and support between husbands and wives and can improve the ability of the couple to cope with internal and external pressure (21). However, excessive dyadic stress destroys the homeostasis, health, and functioning of both spouses, and over time will make nurses with two children more prone to higher degrees of job burnout. The survey results showed that the psychological capital score of nurses with two children was negatively correlated with the dyadic stress score $(\mathrm{P}<0.01)$, indicating that a higher psychological capital level was associated with a lower dyadic stress level. Dyadic stress is a unique form of social pressure, commonly faced by nurses with two children and their spouses. Psychological capital, as an individual's positive psychological resource, can improve the coping ability of nurses who have had two children and can also improve the level of dual support and the relationship with their spouse, thereby reducing the level of dyadic stress.

\section{The mediating role of psychological capital between dyadic stress and job burnout in nurses with two children}

The results of this survey showed that psychological capital played a mediating role between the dyadic stress and job burnout of nurses with two children, similar to previous results reported in the literature $(7,22)$. Our results indicate that psychological capital not only has a direct negative predictive effect on job burnout but also can be used as an intermediary variable for dyadic stress affecting job burnout. That is, the direct predictive effect of dyadic stress in nurses with two children on job burnout also includes the regulating effect of psychological capital. Because dyadic stress is the shared pressure between partners, appropriate dyadic stress is beneficial for improving the benign interaction between partners, enhancing the support between partners, and helping nurses with two children cope with work pressure, thereby reducing job burnout. However, excessive dual pressure will cause adverse mental and physical consequences in nurses who have two children, leading to negative psychological emotions, increased dissatisfaction with work, and eventual burnout. Nurses with a high level of psychological capital have higher selfefficacy and self-confidence in completing their clinical nursing work and can face difficulties and setbacks at work with a positive attitude. At the same time, they are more satisfied with their nursing work, are optimistic about their career development prospects, and have a higher sense of work accomplishment, which can also reduce job burnout. Therefore, hospital nursing managers should pay attention to the relationship between dyadic stress, psychological capital, and job burnout in the particular case of nurses with two children and improve nurses' psychological capital levels through psychological training and intervention projects. At the same time, the dyadic stress of nurses with two children can be reduced through the implementation of family-friendly policies and work support policies.

In summary, nurses with two children demonstrate a relatively high level of dyadic stress and job burnout. Psychological capital plays a partial mediating role between dyadic stress and job burnout. Therefore, reducing dyadic stress and increasing the level of psychological capital are conducive to alleviating job burnout.

\section{Acknowledgments}

Funding: None.

\section{Footnote}

Reporting Checklist: The authors have completed the SURGE reporting checklist. Available at https://dx.doi. org/10.21037/tp-21-375

Data Sharing Statement: Available at https://dx.doi. org/10.21037/tp-21-375

Conflicts of Interest: All authors have completed the ICMJE uniform disclosure form (available at https://dx.doi. org/10.21037/tp-21-375). The authors have no conflicts of interest to declare.

Ethical Statement: The authors are accountable for all aspects of the work in ensuring that questions related to the accuracy or integrity of any part of the work are appropriately investigated and resolved. All procedures performed in this study involving human participants were in accordance with the Declaration of Helsinki (as revised in 2013). The study was approved by the Medical Ethics Committee of the Sixth People's Hospital affiliated with Shanghai Jiaotong University [2021-KY-70(K)] and informed consent was taken from all the participants.

Open Access Statement: This is an Open Access article distributed in accordance with the Creative Commons 
Attribution-NonCommercial-NoDerivs 4.0 International License (CC BY-NC-ND 4.0), which permits the noncommercial replication and distribution of the article with the strict proviso that no changes or edits are made and the original work is properly cited (including links to both the formal publication through the relevant DOI and the license). See: https://creativecommons.org/licenses/by-nc-nd/4.0/.

\section{References}

1. Lin JL, Lin YJ, Chen CR, et al. Work stress of nurses returning to work after the second childbirth and its influencing factors. Chinese Nurs Manag 2020;20:1523-7.

2. Xu FX, Huang YL, Li YQ, et al. The current situation of work and family conflict of female nurses with a second child. Chinese J Nurs 2019;54:1682-7.

3. Yin L, Li JH, Zhang S, et al. Influence of work family conflict and psychological capital on job burnout of nurses in emergency department. Occup Heal 2020;36:2742-6.

4. Zhu YM, Liu P, Yan J, et al. Effects of psychological capital and work-family conflict on job burnout of otolaryngological nurses. Occup Heal 2020;36:70-4.

5. Tang ZB, Hu QZ. A review of binary stress and coping in intimate relationship. Soc Psychol 2015;30:39-45.

6. Luhthans F, Luhthans KW, Luhthans BC, et al. Positive psychological capital: Beyond human and social capital. Bus Horiz 2004;47:45-50.

7. Yang YF, She DL, Chen B, et al. The mediating effect of nurses' psychological capital between job stress and job burnout. J Nurs 2020;27:66-70

8. Min M, Gu AL, Yang R. Effect of psychological capital on job burnout and job satisfaction of pediatric nurses. Indu Health Occup Dis 2020;46:41-4.

9. Kurosawa T, Yokotani K. Validation of the Japanese Version of the Multidimensional Stress Questionnaire for Couples: Factor Structure, Validity and Reliability. J Relatsh Res 2018;9:1-10. doi: 10.1017/jrr.2018.15.

10. Li XM, Liu YJ. Investigation on job stressors and job burnout of nurses. Chinese J Nurs 2000;35:645-9.

11. Luo H, He ZH. Reliability and validity analysis of

Cite this article as: Zhu X, Shen L, Du P, Guan J. The mediating role of psychological capital between Dayadi stress and job burnout in female nurses with two children. Transl Pediatr 2021;10(10):2449-2458. doi: 10.21037/tp-21-375 psychological capital questionnaire in nurses. Chinese J Behav Medic Brain Sci 2010;19:853-4.

12. Wen ZL, Ye BJ. Analyses of Mediating Effects: The Development of Methods and Models. Advances in Psychological Science 2014;22:731-45.

13. Wu ML. Structural equation modeling: operation and application of Amos (2nd Edition). Chongqing: Chongqing University Press, 2010:39-42.

14. Xu Y, Chen YX, Yang XM. The influence of psychological capital on subjective well-being of nurses in a tertiary hospital. J Bengbu Medic College 2020;45:113-7.

15. Zhu YP, Ji BJ, Zhou JZ. Study on influencing factors and correlation of psychological capital, coping style and job performance of nurses. J Adva Nurs Educa 2019; 34:1382$5,1414$.

16. Qu LB, Wang FF, Bai XY, et al. The relationship among psychological flexibility, coping style and job burnout of nurses. Chinese J Behav Medic Brain Sci 2019;28:144-8.

17. Zhang CC, Xin HX. Multiple mediating roles of family function and resilience in the relationship between job burnout and depressive symptoms of orthopedic nurses. Occup Heal 2020;36:26-9.

18. Cheng S, Xiong ZF, Cai Y, et al. Meta analysis on Influencing Factors of job burnout of Chinese nurses. Occup Heal 2020;36:102-6.

19. Nie SJ, Li S. Investigation on the status quo of nurses' Job Burnout and its influencing factors in Harbin. China Hos Manag 2019;39:69-71.

20. Ji JJ, Chen ZH. Investigation on the correlation between psychological capital and job burnout and coping style of psychiatric nurses. Chinese J Prac Nurs 2020;36:2298-302.

21. Ding CG, Mei YX, Lin BL, et al. The application of binary coping in patients with chronic diseases and their spouses. Chinese J Nurs 2018;5:626-30.

22. Liu SJ, Zhao H, Wang TY, et al. The influence of work stress and psychological capital on Job Burnout of university teachers. China Voca Medic 2020;47:282-5.

(English Language Editor: D. Fitzgerald) 